\title{
Outcome of delayed surgery in developmental hip dysplasia in a tertiary care setting
}

Mohammad Khabti Alnamshan, Ayman H. Jawadi, Yazeed Adeeb Alshoaibi, Afaf Moukaddem*

King Saud Bin Abdulaziz University for Health Sciences, King Abdulaziz Medical City

*Corresponding author: Afaf Moukaddem, email: afafmoukaddem@gmail.com, Telephone: 966-11-429-9999

\begin{abstract}
:
Background: The delay in the detection of developmental dysplasia of the hip (DDH) can lead to incomplete hip stabilization and poor outcomes. This might also infer that the delay in DDH surgery can also be associated with unfavorable consequences. The purpose of this study was to compare the outcome of delayed versus early surgery on DDH patients with respect to clinical and radiological factors. Methods: This is a retrospective cohort study in which the charts of patients who underwent DDH surgery and whose age was less than 5 years at the date of referral to the orthopedic clinic, between 2008 and 2011 were reviewed. Results: This study included 62 patients, 34 of which presented with unilateral joint involvement and 28 affected bilaterally. Half of the patients underwent early surgeries ( $<6$ months) and the other half had delayed surgeries ( $\geq 6$ months).

Post-operatively the range of motion was significantly limited in the late surgery group $(\mathrm{P}=0.001)$. Limping gait was also significantly associated with late surgery $(\mathrm{P}=0.005)$.

Radiological abnormalities of all the X-Ray findings didn't reveal any statistically significant difference between early and delayed surgery except for the reduction in acetabular angle in the right hip post-op $(\mathrm{P}=0.04)$. Conclusion: Delayed DDH surgery can lead to a worse clinical outcome, physical disability and possible radiological effects on the patients. Poor outcome was significantly associated with the timing of the surgery. It is therefore recommended to perform DDH surgeries as early as possible to decrease the morbidity and prevent adverse clinical and radiological outcomes.
\end{abstract}

Key words: developmental dysplasia of the hip; surgery; pediatrics

\section{Introduction:}

Developmental dysplasia of the hip (DDH) is a dislocation of the hip, which is usually found at birth, but can also be detected later in life ${ }^{(1}$ 'The hip joint which is a synovial ball-andsocket joint articulates two boney parts, the femoral head and the acetabulum of the pelvic bone, which is a crucial component of hip stability ${ }^{(2)}$. In this condition, the acetabulum is too shallow, and the femoral head may slip out affecting one or both joints ${ }^{(1)}$. The incidence of DDH varies and is reported to be 1 to 5 per 1000 children $^{(3-5)}$.Risk factors of DDH include low amniotic fluid levels, being the first child, female gender, breech position of the baby during delivery and family history ${ }^{(5-7)}$ - As for diagnosis, it is mainly based on clinical examination and ultrasound ${ }^{(8,9)}$.

Ultrasonography is used in DDH to monitor the condition especially in high-risk children following treatment ${ }^{(5)}$. One of these radiologic parameters is the Shenton's line used in the diagnosis of acetabular dysplasia which is smooth in the normal hip and steps off in DDH (10). A high acetabular index might also indicate hip dysplasia $(10,11)$. Adding to the radiological parameters, the femoral head should be in the lower medial quadrant formed by the Hilgenreiner's and Perkin's lines ${ }^{(11)}$.

Treatment of DDH differs according to the patient's age of presentation. The standard treatment for infants less than 6 months of age is the Pavlik harness which is used to hold the hip joint as the child grows and mainly aims to reduce the hip ${ }^{(12,13)}$; an abduction brace has also been indicated for use in infants less than 6 months of age (14). If the patient presents between 6 and 18 months of age or in case the harness was not beneficial, a closed surgical reduction is indicated, and a cast is needed afterward ${ }^{(15)}$. However, in refractory cases and in children older than 18 months an open reduction is required ${ }^{(16-18)}$. As for children older than 3 years, several types of pelvic osteotomies are performed according to the patient's age ${ }^{(19)}$.

DDH can be easily corrected once detected and treated, otherwise the condition might not become evident until the child starts walking after which the correction of the dislocation is more complicated and yields poorer outcomes (20). In this case, this treatable condition can progress into an anatomically abnormal hip which is a major source of disability in 
children ${ }^{(2,20)}$. This in addition to the higher costs of treatment associated with late diagnosis ${ }^{(21)}$. Hip pain, permanent waddling gait, limitation of hip abduction, avascular necrosis and poor functional outcomes are also among the complications of untreated $\mathrm{DDH}^{(20 \text {, }}$ 22). Also, a major long-term outcome of DDH is the increase in the risk of developing hip osteoarthritis before the age of $60{ }^{(23-25)}$. The delay of treatment or surgery as in the case of underdiagnoses or being on a long surgery waiting list might also pose similar risks and complications.

The purpose of this study was to compare the outcomes of delayed versus early surgery in DDH patients on several factors including number of procedures, gait, range of motion "ROM" and radiological X-Ray findings including Shenton's Line, H\&P lines, ossification nucleus, and the acetabular angle.

\section{Subjects and methods:}

This is a retrospective cohort study which was conducted in the orthopedic surgery department of King Abdul-Aziz medical city (KAMC), a tertiary care hospital in Riyadh, Saudi Arabia. It was approved by the ethics committee of King Abdullah International Medical Research Center (KAIMRC). It included pediatric patients younger than 5 years at the date of referral to the orthopedic clinic who underwent DDH surgery from January 2008 to December 2011. Patients belonged to two groups; the first group included all patients who waited for 6 months or more to undergo the surgery or if the patient shifted from one type of surgery to another as they grew older. The second group included an equal number of patients who had their surgery done within less than 6 months of waiting. The DDH surgeries included in this study were as follows depending on the patient's age: closed reduction and spica application for 6-18 months old, open hip reduction for 18 months-3 years and different types of pelvic osteotomies for older children.

Data pertaining to clinical and radiological factors were extracted from patient medical records. The following clinical variables were assessed: number of procedures performed, gait (normal, limping), and range of motion (ROM) (normal, limited). In addition, radiological variables of both joints pre-and post-operatively were assessed including Shenton's Line, the ossification nucleus, Hilgenreiner's and Perkin's lines(H\&P) and the acetabular angle through X-ray examination. Acetabular angle improvement was measured as the difference in acetabular angle pre- and post-operatively and as the percent reduction in acetabular angle.

\section{Statistical analysis}

For data entry and analysis, the Statistical Package for Social Sciences (SPSS), version 22 was used. Categorical variables were presented as frequencies(percentages) and continuous data were presented as mean \pm standard deviation (SD). To study the association between timing of the surgery and the other clinical and radiological outcomes, Chi squared test or independent sample t-test were performed. The level of significance was set at $\mathrm{P}$-value less than 0.05 .

\section{Results:}

This study included 62 patients, 34 presenting with unilateral joint involvement and 28 bilateral with a total of 90 hips. Half of the subjects had early surgeries and the rest had late surgeries (Table 1). Most of the patients $(83.9 \%)$ were females. Mean age at presentation was 18 months and the mean age at operation was almost 26 months (Table 1).

The number of procedures was not significantly different among study subjects who had an early surgery and those who had late surgeries $(P=0.45)$ (Table 2). Limping gait post-operatively was significantly higher among late surgery group (35.5\%) in comparison with those who had an early operation $(6.5 \%) \quad(\mathrm{OR}=7.9, P=0.005)$ (Table $2)$. Post-operative ROM was also significantly associated with the timing of surgery; full ROM was higher in the early surgery group $(96.8 \%)$ versus the late surgery group $(64.5 \%)$ $(\mathrm{OR}=10.3)(P=0.001)$ (Table 2).

Shenton's line of the right hip was normal in almost all the patients in the early and late group with 100 and $93.5 \%$ respectively $(P=0.33)$ (Table 2). Shenton's line of the left hip post-operatively was normal in all patients in both groups. Ossification nucleus of the right hip post-operatively was normal in all patients in the early surgery group, compared to $87.1 \%$ patients having normal ossification 
nucleus in those with late surgery $(P=0.23)$ (Table 2). In the left hip $97 \%$ of patients were having normal ossification nucleus in early surgery, compared to $87.1 \%$ in late surgery $(P=0.26)$ (Table 2).

$\mathrm{H} \& \mathrm{P}$ lines of the right hip post-operatively were normal in all early surgery patients compared to $97 \%$ patients in late surgery $(P=$ 1). H\&P lines of the left hip post-operatively were normal in all patients in both groups (Table 2).

Acetabular angle difference in the left hip post-operatively was $13.7 \pm 7.3$ in the early surgery group, and $17.5 \pm 10.5$ in the late surgery $(P=0.11)$ (Table 2$)$. Those in the early surgery group had an acetabular angle difference in the right hip post-operatively of $10.7 \pm 9.4$ and $15.4 \pm 10.1$ in late surgery $(P=0.07)$. Reduction of Acetabular angle for the left hip post-operatively was $37 \%$ in those in the early surgery group versus $44 \%$ in the late surgery $(P=0.22)$. For the right hip, acetabular angle reduction post-operatively in the early and late surgery groups was $29 \%$ and $40 \%$ respectively $(P=0.04)$.

Table 1 General Characteristics of Patients who underwent DDH surgery $(n=62)$

\begin{tabular}{|ll|}
\hline Variable & $\mathrm{n}(\%)$ \\
\hline Gender & \\
Male & $10(16.1)$ \\
Female & $52(83.9)$ \\
& \\
Age of presentation (in months) & $18.45 \pm 10.7$ \\
Age at operation (in months) & $25.8 \pm 13.6$ \\
Timing of surgery & \\
Early (<6 months) & $31(50)$ \\
Late ( $\geq 6$ months) & $31(50)$ \\
\hline
\end{tabular}

\section{Discussion:}

The treatment or correction of DDH is a vital step in avoiding any future complications and poor outcomes. In addition to the importance of early detection of DDH ${ }^{(20)}$ in favoring the desirable outcomes of the intervention, the same applies to the timing the surgery was performed to correct the condition.

This study was the first to address the outcome of delayed surgery of DDH in a wide range of ages ranging from 6 months to 5 years in Saudi Arabia and the region. It compared several outcomes of delayed and early DDH surgery, thus shedding the light on the importance of early intervention in treating
DDH. Most cases were females, which was concordant with other studies ${ }^{(5,7)}$.

When comparing early and delayed surgery, some less favorable clinical findings were significantly associated with the delayed surgery. Abnormal limping gait was significantly more evident among the delayed surgery group which can be explained by the fact that pathological hip deformities led to abnormal gait deviations ${ }^{(26)}$.

Likewise, ROM was also significantly limited in the delayed surgery compared to the early surgery. This might imply that the later the surgery is done, the poorer the functional outcomes in terms of gait and $\operatorname{ROM}^{(2,3,26)}$.

Regarding secondary surgical procedures following the hip correction, some studies reported that more than half of the patients required further surgeries ${ }^{(27,28)}$. In this study, there was no significant difference between the two groups regarding the number of procedures undertaken by patients which might be attributed to the difference in the surgical skills between the orthopedic surgeons who performed the procedures, the degree of dysplasia and the complications occurring intra and post-operatively.

Radiographic parameters were shown to be valid and reliable in measuring the long-term outcomes ${ }^{(29)}$. Although acetabular index has been shown to improve in all hips after evaluation (30), the radiological findings (Shenton's Line, Ossification Nucleus, H\&P lines and acetabular angle) in this study showed no significant difference between the early and late surgery groups except for the acetabular angle improvement post-operatively in percentage for the left hip.

A study similar to ours explored the outcomes of neglected DDH surgery after walking age and concluded that technically it is a more difficult procedure that requires high expertise (30). However, it didn't compare the outcome between early and late surgery which makes comparison between our results and those found by the other authors seem to be unreliable ${ }^{(30)}$. Some limitations of this study were the small sample size which might have masked any actual association between the timing of the surgery and the outcomes. This in addition to bei ng a single-centered study which might not apply to other institutions and a longer term follow up is needed for better outcome assessment. 
Mohammad Alnamshan et al.

Table 2 Frequency distributions and bivariate associations of the clinical and radiological findings in early and late surgery

\begin{tabular}{|c|c|c|c|c|c|}
\hline Variable & $\begin{array}{l}\text { Early surgery } \\
(\mathrm{N}=31) \\
n(\%)\end{array}$ & $\begin{array}{l}\text { Late surgery } \\
(\mathrm{N}=31) \\
n(\%)\end{array}$ & $\begin{array}{l}\text { Total } \\
n(\%)\end{array}$ & Odds ratio & P-value \\
\hline \multicolumn{6}{|l|}{$\begin{array}{l}\text { Number } \\
\text { procedures }\end{array}$} \\
\hline $1-3$ & $28(90.3)$ & 26(83.9) & $54(87.1)$ & 0.57 & 0.45 \\
\hline$\geq 4$ & $3(9.7)$ & $5(16.1)$ & $8(12.9)$ & & \\
\hline \multicolumn{6}{|l|}{ Gait } \\
\hline Normal & $29(93.5)$ & $20(64.5)$ & $49(79)$ & 7.9 & $0.005 *$ \\
\hline Limping & $2(6.5)$ & $11(35.5)$ & $13(21)$ & & \\
\hline \multicolumn{6}{|l|}{$R_{O M}{ }^{1}$} \\
\hline Full & $30(96.8)$ & $20(64.5)$ & $50(80.6)$ & 10.3 & $0.001 *$ \\
\hline Limited & $1(3.2)$ & $11(35.5)$ & $12(19.4)$ & & \\
\hline \multicolumn{6}{|l|}{$\begin{array}{l}\text { Shenton line of } \\
\text { Right joint }^{2}\end{array}$} \\
\hline $\mathrm{N}^{3}-\mathrm{N}$ & $10(32.3)$ & $8(25.8)$ & $18(29)$ & 2.2 & 0.33 \\
\hline $\mathrm{D}^{4}-\mathrm{N}$ & $21(67.7)$ & 2167.7 ) & $42(67.7)$ & & \\
\hline D-D & $0(0)$ & $2(6.5)$ & $2(3.2)$ & & \\
\hline \multicolumn{6}{|l|}{$\begin{array}{l}\text { Shenton line of left } \\
\text { joint }^{2}\end{array}$} \\
\hline \multicolumn{6}{|l|}{$\mathrm{N}^{3}-\mathrm{N}$} \\
\hline \multirow[t]{2}{*}{$\mathrm{D}^{4}-\mathrm{N}$} & $6(19.4)$ & $7(22.6)$ & $13(21)$ & 0.09 & 0.75 \\
\hline & $25(80.6)$ & $24(77.4)$ & $49(79)$ & & \\
\hline \multicolumn{6}{|l|}{$\begin{array}{l}\text { Ossification nucleus } \\
\text { of left joint }^{2}\end{array}$} \\
\hline \multicolumn{6}{|l|}{$\mathrm{N}^{3}-\mathrm{N}$} \\
\hline$D^{5}-\mathrm{N}$ & $6(19.4)$ & $8(25.8)$ & $14(22.6)$ & 2.7 & 0.26 \\
\hline \multirow{2}{*}{ D-D } & $24(77.4)$ & $19(61.3)$ & $43(69.4)$ & & \\
\hline & $1(3.2)$ & $4(12.9)$ & $5(8.1)$ & & \\
\hline \multicolumn{6}{|l|}{$\begin{array}{l}\text { Ossification nucleus } \\
\text { of right joint }^{2}\end{array}$} \\
\hline \multicolumn{6}{|l|}{$\mathrm{N}-\mathrm{N}$} \\
\hline $\mathrm{N}-\mathrm{D}^{5}$ & $12(38.7)$ & $10(32.3)$ & $22(35.5)$ & 4.3 & 0.23 \\
\hline D-N & $0(0)$ & $1(3.2)$ & 1(1.6) & & \\
\hline \multirow[t]{2}{*}{ D-D } & 19(61.3) & $17(54.8)$ & $36(58.1)$ & & \\
\hline & $0(0)$ & $3(9.7)$ & $3(4.8)$ & & \\
\hline \multicolumn{6}{|l|}{$\begin{array}{l}H \& P \text { lines for right } \\
\text { hip }^{2}\end{array}$} \\
\hline $\mathrm{N}^{3}-\mathrm{N}$ & $12(38.7)$ & $9(29)$ & 21(33.9) & 1.5 & 0.46 \\
\hline$D^{6}-\mathrm{N}$ & 19(61.3) & 21(67.7) & $40(64.5)$ & & \\
\hline D-D & $0(0)$ & $1(3.2)$ & $1(1.6)$ & & \\
\hline \multicolumn{6}{|l|}{$\begin{array}{l}H \& P \text { lines for left } \\
\text { hip }^{2}\end{array}$} \\
\hline $\mathrm{N}-\mathrm{N}$ & $6(19.4)$ & $7(22.6)$ & $13(21)$ & 0.09 & 0.75 \\
\hline$D^{6}-\mathrm{N}$ & $25(80.6)$ & $24(77.4)$ & $49(79)$ & & \\
\hline $\begin{array}{l}\text { Acetabular angle } \\
\text { difference for left } \\
\text { hip }\end{array}$ & $13.7 \pm 7.3$ & $17.5 \pm 10.5$ & - & - & 0.11 \\
\hline
\end{tabular}




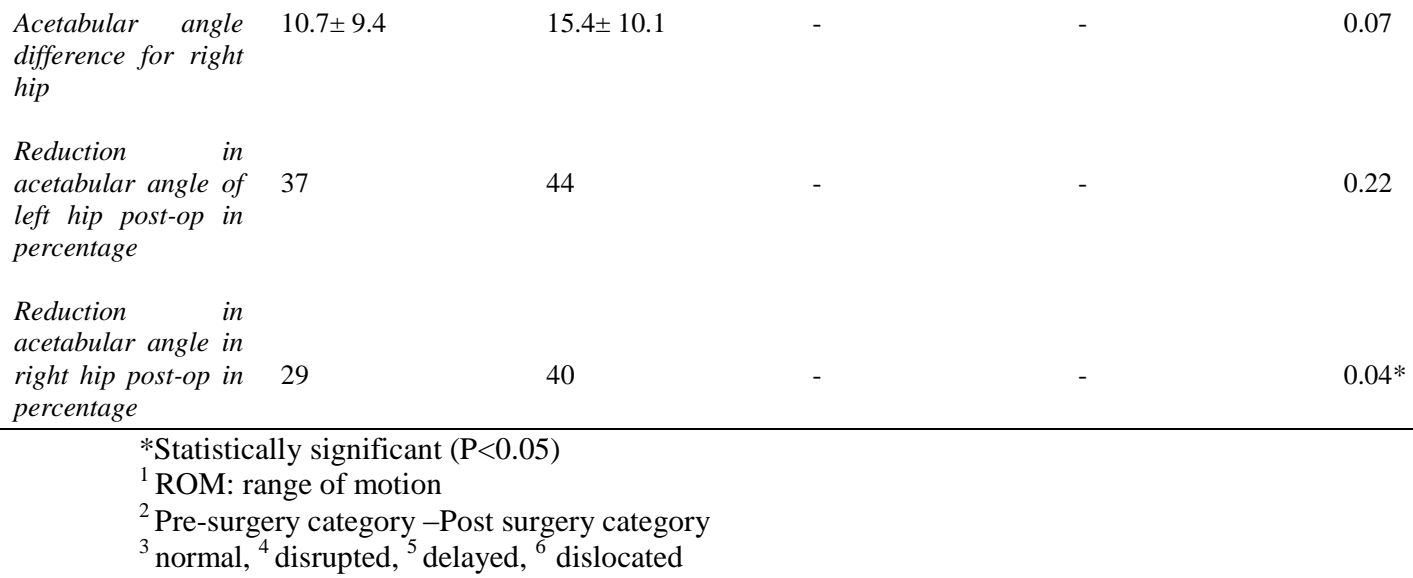

Conclusion / Recommendations:

Delayed DDH surgery seems to carry a poor clinical outcome and physical disability and a possible radiological effect on the patient. We suggest conducting similar multicentered studies that can investigate more cases to compare between the early and late hip surgeries in terms of outcome. We also recommend performing early surgeries in the case of DDH to reduce any poor surgical outcomes and improve the well-being and lifestyle of the DDH patients.

\section{References}

1. Aronsson DD, Goldberg MJ, Kling TF, Roy DR (1994): Developmental dysplasia of the hip. Pediatrics, 94 (2 Pt 1): 201-8.

2. Guille JT, Pizzutillo PD, MacEwen GD (2000): Developmental dysplasia of the hip from birth to six months. J AM Acad Orthop Surg.,8 (4): 232-42.

3. Weinstein, Stuart L (1987): Natural history of congenital hip dislocation (CDH) and hip dysplasia. Clin Orthop Relat Res., 225: 62-76.

4. Bialik V, Bialik GM, Blazer $S$, Sujov $P$, Wiener F, Berant M (1999): Developmental dysplasia of the hip: a new approach to incidence. Pediatrics, 103 (1): 93-9.

5. Schwend RM, Shaw BA, Segal LS (2014): Evaluation and treatment of developmental hip dysplasia in the newborn and infant. Pediatr Clin North Am., 61 (6): 1095-107.

6. Stevenson DA, Mineau G, Kerber RA, Viskochil DH, Scheafer C, Roach JW (2009): Familial predisposition to developmental dysplasia of the hip. J Pediatr Orthop., 29 (5): 463-6.

7. American Academy of Pediatrics (2000): Clinical practice guideline: early detection of developmental dysplasia of the hip. Committee on Quality Improvement, Subcommittee on developmental dysplasia of the hip. American Academy of Pediatrics. Pediatrics, 105 (4 Pt 1): 896-905.

8. Rhee PC, Woodcock JA, Clohisy JC, Millis M, Sucato DJ, Beale PE, Trousdale RT, Siera RJ (2011): The Shenton line in the diagnosis of acetabular dysplasia in the skeletally mature patient. J Bone Joint Surg., 93: 35-9.

9. Williams D, Protopapa E, Stohr K, Hunter JB, Roposch A (2016): The most relevant diagnostic criteria for developmental dysplasia of the hip: a study of British specialists. BMC Musculoskelet Disord., $17: 38$

10. Gillingham BL, Sanchez AA, Wenger DR (1999): Pelvic osteotomies for the treatment of hip dysplasia in children and young adults. J Am Acad Orthop Surg., 7 (5): 325-37.

11. Scoles PV, Boyd A, Jones PK (1987): Roentgenographic parameters of the normal infant hip. J Pediatr Orthop., 7 (6): 656-63.

12. Cashman JP, Round J, Taylor G, Clarke NM (2002): The natural history of developmental dysplasia of the hip after early supervised treatment in the Pavlic harness. A prospective, longitudinal follow-up. J Bone Joint Surg Br., 84 (3): 418-25.

13. Peled E, Bialik V, Katzman A, Eidelman M, Norman D (2008): Treatment of Graf's ultrasound class III and IV hips using Pavlik's method. Clin Orthop Relat Res., 466 (4): 8259. 
14. Wahlen R, Zambelli PY (2015): Treatment of the Developmental Dysplasia of the Hip with an Abduction Brace in Children up to 6 Months Old. Adv Orthop., 2015:103580.

15. Malvitz TA, Weinstein SL (1994): Closed reduction for congenital dysplasia of the hip. Functional and radiographic results after an average of thirty years. J Bone Joint Surg Am., 76 (12): 1777-92.

16. Morcuende JA, Meyer MD, Dolan LA, Weinstein SL (1997): Long-term outcome after open reduction through an anteromedial approach for congenital dislocation of the hip. J Bone Joint Surg Am., 79 (6): 810-817.

17. Ucar DH, Isiklar ZU, Stanitski CL, Kandemir U, Tumer Y (2004): Open reduction through a medial approach in developmental dislocation of the hip: a followup study to skeletal maturity. J Pediatr Orthop., 24(5): 493-500.

18. Chang CH, Kao HK, Yang WE, Shih CH (2011): Surgical results and complications of developmental dysplasia of the hip-one stage open reduction and Salter's osteotomy for patients between 1 and 3 years old. Chang Gung Med J., 34(1): 84-92.

19. Ryan MG, Johnson LO, Quanbeck DS, Minkowitz B (1998): One-stage treatment of congenital dislocation of the hip in children three to ten years old. Functional and radiographic results. J Bone Joint Surg Am., 80 (3): 336-44.

20. Pun $S$ (2016): Hip dysplasia in the young adult caused by residual childhood and adolescent-onset dysplasia. Curr Rev Musculoskelet Med., 9(4): 427-34.

21. Woodacre $T$, Dhadwal A, Ball $T$, Edwards C, Cox PJ (2014): The costs of late detection of developmental dysplasia of the hip. J Child Orthop., 8(4): 325-32.
22. Thomas S (2015): A review of long-term outcomes for late presenting developmental hip dysplasia. J Bone Joint, 97-B: 729-33.

23. Jacobsen S, Sonne-Holm S (2005): Hip dysplasia: a significant risk factor for the development of hip osteoarthritis. A crosssectional survey. Rheumatology (Oxford), 44 (2): 211-8.

24. Millis, MB, Poss R, Murphy SB (1992): Osteotomies of the hip in the prevention and treatment of osteoarthritis. Instr Course Lect., 41: $145-54$.

25. Lievense AM, Bierma Zeinstra SMA, Verhagen AP, Verhaar JAN, Koes BW (2004): Influence of hip dysplasia on the development of osteoarthritis of the hip. Ann Rheum Dis., 63(6): 621-6.

26. Simonsen EB (2014): Contributions to the understanding of gait control. Contributions to the understanding of gait control. Dan Med J., 61(4): B4823.

27. Zionts LE (1986): Treatment of congenital dislocation of the hip in children between the ages of one and three years. $J$ Bone Joint Surg Am., 68(6): 829-46.

28. Mardam-Bey TH, MacEwen GD (1982): Congenital hip dislocation after walking age. J Pediatr Orthop., 2(5): 478-86.

29. Pedersen DR, Lamb CA, Dolan LA, Ralston HM, Weinstein SL, Morcuende JA (2004): Radiographic measurements in developmental dysplasia of the hip: reliability and validity of a digitalizing program. $\mathrm{J}$ Pediatr Orthop., 24(2): 156-60.

30. El-Sayed M. Ahmed T, Fathy S, Zyton H (2012): The effect of Dega acetabuloplasty and Salter innominate osteotomy on acetabular remodeling monitored by the acetabular index in walking DDH patients between 2 and 6 years of age: short- to middle-term follow-up. J Child Orthop., 6(6): 471-7. 